\section{Hiatal Hernia as a Heart Failure Masquerader}

Sir,

A 57-year woman presented with shortness of breath on exertion, paroxysmal nocturnal dyspnea, and indigestion-like pain. Previous history included treated hypertension, Barrett's oesophagus and iron deficiency anemia. The physical examination was normal. Biochemical profile showed hemoglobin of $133 \mathrm{~g} / \mathrm{L}$, raised $\mathrm{HbA} 1 \mathrm{C}$ and a normal NT-BNP level of $145 \mathrm{pg} / \mathrm{ml}$. Electrocardiogram (ECG) showed sinus rhythm with normal intervals.

An echocardiogram was performed, which showed suboptimal image quality; but gave the impression of dimensionally normal left ventricle with dis-coordinated contraction and impaired systolic function. The visual estimate ejection fraction was reported as 25-30\%. There was grade Il diastolic dysfunction.

Cardiac MRI was then arranged to evaluate systolic dysfunction further. The MRI demonstrated a large sliding type hiatus, hernia partly splinting and compressing the posterior surface of left ventricle (Figures 1 and 2). There was mild systolic impairment of left ventricle, nonspecific apical trabeculation and no scarring. The patient was referred for, and awaits hernia repair.

Hiatal hernia is a common condition with reported prevalence of $0.8-2.9 \%$ of all cases undergoing upper gastrointestinal endoscopy, and is not uncommonly missed on initial workup., ${ }^{1,2}$

Hiatal hernia, especially large, can infrequently present with breathlessness and chest pain, including paroxysmal nocturnal dyspnea and rarely pulmonary edema. ${ }^{1,3}$ There may be pointers in history, especially relation of symptoms to eating, bowel movements orstanding.

Potential explanations for dyspnea are: interference with diaphragm movement, ventilation and perfusion disturbances, reflux asthma, coexistent obesity and mechanical effects of hiatal hernia like left atrial compression. ${ }^{4}$

A case of large hiatal hernia, presented with dyspnea and found to be compressing the left atrium and right pulmonary vein with high estimated pulmonary artery pressure, has been reported. ${ }^{3}$ Siu et al. reported a large hiatal hernia that caused compression of left atrium in a patient with recurrent episodes of acute cardiac failure. ${ }^{1}$ Chau et al. demonstrated hiatal hernia as being the cause of acutely presenting angina in an emergency department visit. ${ }^{4}$ In addition to left atrial compression, evidence of pulmonary venous, and coronary sinus compression by large hiatal hernias has been found. ${ }^{3}$ In this patient, the hernia was compressing and splinting left ventricle. Direct left ventricular compression has not been reported previously to our knowledge. Post-prandial contrast transthoracic echocardiography or MRI may be helpful in cases with compression of cardiac chambers by hernia. Exercise capacity and functional class improve following resolution of cardiac compression and improvement in filling after hernia repair. ${ }^{5}$

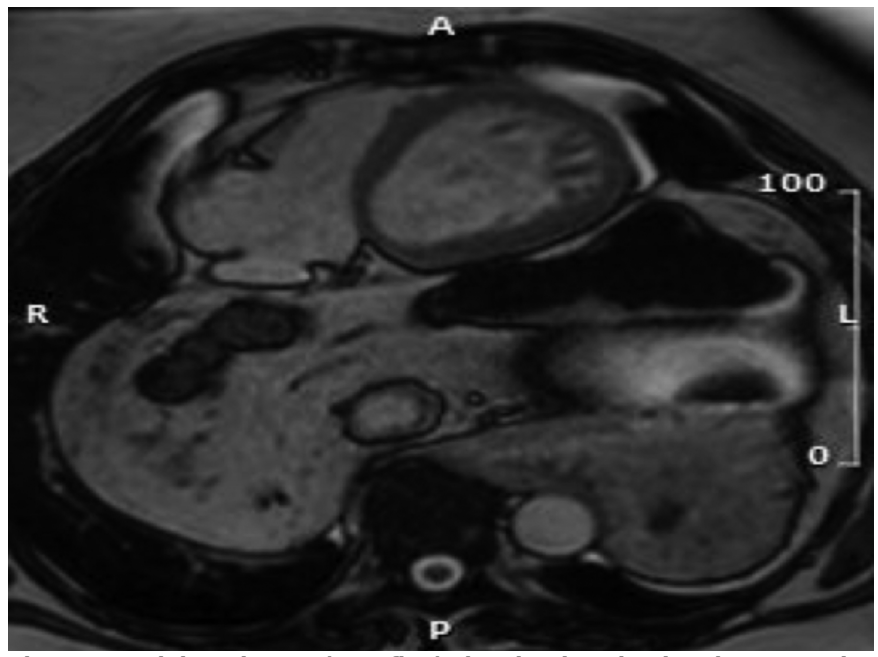

Figure 1: Axial MR image (Truefisp) showing hernia abutting posterior left ventricularsurface.

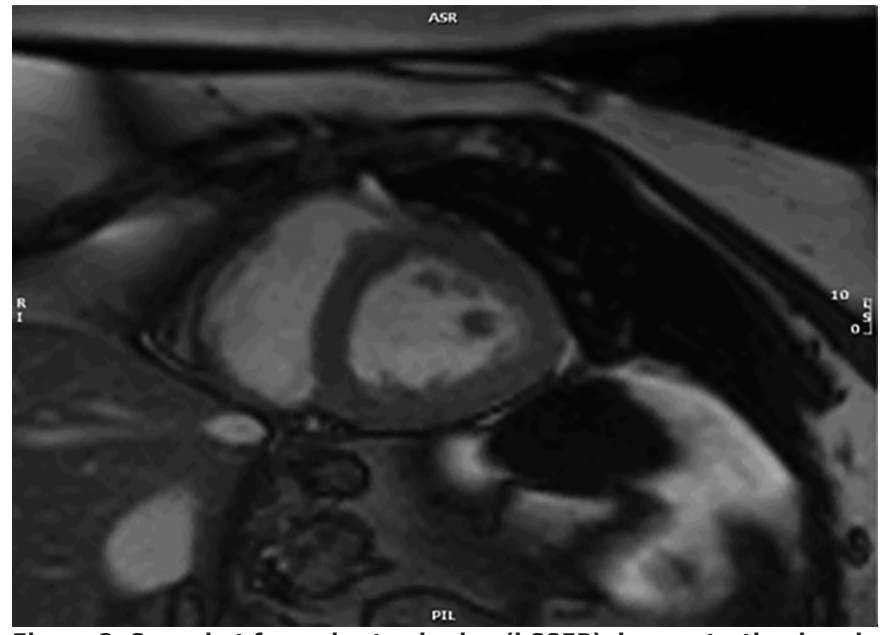

Figure 2: Snapshot from short axis cine (bSSFP) demonstrating hernia partially compressing left ventricle.

\section{CONFLICT OF INTEREST:}

The authors declared no conflict of interest.

\section{AUTHORS' CONTRIBUTION:}

UG: Wrote the report, did the literature search, performed the MRI.

$\mathrm{RH}$ : Proofread and did guidance on case report and clinical follow-up of patient.

\section{REFERENCES}

1. Siu CW, Jim MH, Ho HH, Chu F, Chan HW, Lau CP, et al. Recurrent acute heart failure caused by sliding hiatus hernia. Postgraduate Med J 2005; 8(954): 268-9. doi: 10.1136/pgmj.2004.023416.

2. Khanbabaee G, Imanzadeh F, Kiani M. Hiatal hernia as a 
mysterious diagnosis: A Case Report. Int J Pediatr 2015; 3:4-1(19).

3. Bunel V, Mordant P, Ribeiro L, Crestani. Giant hiatal hernia: Beware of the supine ICU chest X-ray. BMJ Case Rep 2017; 2017:bcr2017219668. doi:10.1136/bcr-2017-219668.

4. Chau AM, Ma RW, Gold DM. Massive hiatus hernia presenting as acute chest pain. Intern Med J 2011; 41(9):704-5. doi: 10.1111/j.1445-5994.2011.02551.x.

5. Milito P, Lombardi M, Asti E, Bonitta G, Fina D, Bandera F, et al. Influence of large hiatus hernia on cardiac volumes. A prospective observational cohort study by cardiovascular magnetic resonance. Int J Cardiol 2018; 268:241-4. doi: 10.1016/j.ijcard.2018.05.016.
Uzma Gul and Robert Huggett

Department of Cardiology, Russells Hall Hospital, Pensnett Road, Dudley, United Kingdom

Correspondence to: Dr. Uzma Gul, Department of Cardiology, Russells Hall Hospital, Pensnett Road, Dudley, United Kingdom

E-mail: uzma.12@hotmail.com

Received: July 06, 2021; Revised: January 30, 2021;

Accepted: February 14, 2021

DOI: https://doi.org/10.29271/jcpsp.2021.10.1250 